\title{
Facilitating harmonized data quality assessments. A data quality framework for observational health research data collections with software implementations in $\mathrm{R}$
}

Carsten Oliver Schmidt ${ }^{*}$, Stephan Struckmann ${ }^{1}$, Cornelia Enzenbach², Achim Reineke ${ }^{3}$, Jürgen Stausberg ${ }^{4}$, Stefan Damerow ${ }^{5}$, Marianne Huebner ${ }^{6}$, Börge Schmidt ${ }^{4}$, Willi Sauerbrei ${ }^{7}$ and Adrian Richter ${ }^{7}$

\begin{abstract}
Background: No standards exist for the handling and reporting of data quality in health research. This work introduces a data quality framework for observational health research data collections with supporting software implementations to facilitate harmonized data quality assessments.

Methods: Developments were guided by the evaluation of an existing data quality framework and literature reviews. Functions for the computation of data quality indicators were written in $\mathrm{R}$. The concept and implementations are illustrated based on data from the population-based Study of Health in Pomerania (SHIP).

Results: The data quality framework comprises 34 data quality indicators. These target four aspects of data quality: compliance with pre-specified structural and technical requirements (integrity); presence of data values (completeness); inadmissible or uncertain data values and contradictions (consistency); unexpected distributions and associations (accuracy). R functions calculate data quality metrics based on the provided study data and metadata and R Markdown reports are generated. Guidance on the concept and tools is available through a dedicated website.

Conclusions: The presented data quality framework is the first of its kind for observational health research data collections that links a formal concept to implementations in R. The framework and tools facilitate harmonized data quality assessments in pursue of transparent and reproducible research. Application scenarios comprise data quality monitoring while a study is carried out as well as performing an initial data analysis before starting substantive scientific analyses but the developments are also of relevance beyond research.
\end{abstract}

Keywords: Data quality, Observational health studies, Data quality indicators, Data quality monitoring, Initial data analysis, $R$

\footnotetext{
* Correspondence: carsten.schmidt@uni-greifswald.de

${ }^{1}$ Institute for Community Medicine, Department SHIP-KEF, University

Medicine Greifswald, Greifswald, Germany

Full list of author information is available at the end of the article
}

C The Author(s). 2021 Open Access This article is licensed under a Creative Commons Attribution 4.0 International License, which permits use, sharing, adaptation, distribution and reproduction in any medium or format, as long as you give appropriate credit to the original author(s) and the source, provide a link to the Creative Commons licence, and indicate if changes were made. The images or other third party material in this article are included in the article's Creative Commons licence, unless indicated otherwise in a credit line to the material. If material is not included in the article's Creative Commons licence and your intended use is not permitted by statutory regulation or exceeds the permitted use, you will need to obtain permission directly from the copyright holder. To view a copy of this licence, visit http://creativecommons.org/licenses/by/4.0/ The Creative Commons Public Domain Dedication waiver (http://creativecommons.org/publicdomain/zero/1.0/) applies to the data made available in this article, unless otherwise stated in a credit line to the data. 


\section{Background}

Achieving a high data quality is a precondition for valid research results in all empirical sciences. Informative data quality indicators should inform data analysts about the "degree to which a set of inherent characteristics of data fulfils requirements" (ISO 8000). Data quality indicators thus describe actual and potential deviations from defined requirements such as formal compliance with pre-specified data structures, completeness, and the correctness of data values. Appropriately designing, assessing and quantifying data quality is of relevance during the entire research data life cycle. Already before the start of a data collection, having a clear understanding of data quality and its assessment should influence study design and data management. During study conduct, results of data quality assessments inform about the successful implementation of examinations, thereby triggering quality control and quality assurance activities such as data cleaning or training measures [1]. Data quality assessments after the end of a data collection influence decisions about data pooling and data harmonization [2], they can be used to benchmark studies and are necessary to safeguard responsible statistical analysis [3, 4].

While many data quality frameworks exist in the medical sciences [5-16], most of them target registries and electronic health records (EHR). These use data that have been generated outside of a research context, e.g. from administrative data. Yet, there is insufficient guidance on conducting data quality assessments for data that have specifically been generated for observational health research.

This lack of guidance is problematic as data quality frameworks for EHR data and registries are not directly applicable to designed research data collections [17]. For example, accessibility and interpretability have been defined as major quality criteria for EHR data [16]. Both are less relevant in research data collections where related issues are commonly solved by an appropriate study design, the standardisation of procedures, the training of examiners, and the implementation of a supporting infrastructure. Furthermore, preconditions for the computation of indicators may differ. Calculating the exact proportion of missing data in a population-based cohort study is based on a known sampling frame with a precisely defined number of study variables for each participant. In contrast, if, for example, information on a defined cardiovascular comorbidity in a patient with diabetes is missing in an EHR data set it is commonly unclear whether this comorbidity has not been diagnosed, examined, or simply not recorded. Therefore, a data quality framework must take specifics of the targeted data body into account.
A data quality framework must also guide the use of metadata and process variables for data quality assessments. Metadata in this context refers foremost to attributes that describe variables and expected data properties such as admissible values or distributional properties. Process variables describe aspects of the data generating process such as time stamps, observers or devices. Process variables are used to detect unexpected associations with study outcomes of interest. Ideally, each data quality indicator is accompanied by a description of the metadata and process variables that are required for its computation.

While a growing number of statistical routines address data quality issues [18-21], particularly in the programming language $\mathrm{R}$ [22-24], these routines are mostly not founded in data quality frameworks. Exceptions for EHR data are the approaches of Kahn et al. [10] within OHDSI [25] and Kapsner et al. [26].

The objectives of this work are twofold: (1) to provide a data quality framework tailored for designed data collections in observational health research, (2) to ease the application of the framework by providing openly available software implementations. All developments were integrated in a web-page to facilitate their successful application.

\section{Methods}

\section{Background}

We built on an existing data quality framework, the 2nd edition of the TMF (Technology, Methods, and Infrastructure for Networked Medical Research) guideline for data quality [11, 14]. TMF is a major umbrella organization for networked medical research in Germany. The guideline was chosen because, unlike other frameworks, it includes data quality indicators, which are of specific relevance for cohort studies. Literature reviews and overviews of data quality concepts in health research $[5-10,27,28]$ informed the development of our framework.

The focus of the presented framework is "intrinsic data quality" [16] which means that "data have quality in their own right". Evaluating intrinsic data quality rests primarily on knowledge about the data generating process. This is in contrast to "contextual data quality" which means that data quality is considered within the context of a particular task, e.g. the analysis of a defined scientific research question. We currently exclude such task- and situation-specific indicators.

\section{Evaluation of the TMF guideline for data quality}

The TMF guideline for data quality was subject to an evaluation by representatives of German generalpopulation cohort studies to assess its suitability for this study type. Details of the evaluation process and results 
are available elsewhere [29]. In total, 43 out of the 51 quality indicators in the guideline have been assessed as being potentially relevant for cohort studies. In total 29 were classified as essential or important (mean evaluation score $<=2$; out of: $1=$ essential, $2=$ important, $3=$ less important, and $4=$ not important) and have been included in the current framework. Metrics of data quality indicators in the TMF guideline are restricted to counts and percentages, yet a broader scope of statistical metrics related to distributions, associations and measures of agreement were considered important for the quantification of aspects of data quality, as was a more specific handling of metadata compared to the TMF guideline. Therefore, novel indicators that cover aspects of descriptive statistics and initial data analysis [3] were added.

\section{Computing data quality with $\mathbf{R}$}

Functions were developed as part of this project in the dataquieR package, available at CRAN [30], to compute data quality indicators, using $R$ as the programming language because of its widespread use and free access [31]. We followed the style guide first published by Hadley Wickham [32]. R scripts were tested on simulated data and on data from several cohort studies, e.g. Study of Health in Pomerania [33], LIFE-Adult-Study [34], and the IDEFICS study [35]. An R Markdown generated website provides access to the concept, dataquieR functions, sample data, metadata descriptions, references, and tutorials [36].

\section{Application example}

The framework and implementations are illustrated using data from the Study of Health in Pomerania (SHIP), a population-based cohort study [33]. We used data from the baseline assessment of SHIP-0 from 1997 to $2001(N=4308)$. The data set comprises variables on: height, weight, and waist circumference from the somatometric examination, systolic and diastolic blood pressure from a blood pressure measurement, and information on smoking, marital status and intake of contraceptives from the computer assisted medical interview. An anonymized dataset was created based on a $50 \%$ random subset of the original sample $(N=2154)$. It is publicly available at [36].

$\mathrm{R}$ Markdown reports were rendered to HTML documents. These provide an overview of the results of the data quality assessment, including tables, and graphs. Modified study data sets are automatically generated to highlight unexpected findings at the level of individual observations with the purpose of simplifying subsequent data management steps.

\section{Results}

Structure of the data quality framework

In accordance with existing data quality concepts $[6,7$, 9], completeness and correctness are the two core aspects of data quality (Table 1). Completeness is represented as a single dimension while correctness is subdivided into the two dimensions consistency and accuracy. The reason for this separation is introduced in the paragraph correctness. A precondition for successfully conducting any data quality assessment is the correct technical setup of study data and metadata. Related aspects are targeted within the integrity dimension.

Each dimension is subdivided into different data quality domains, an overview on dimensions and domains is provided in Table 1 . The domains differ mainly in terms of the methodology used to assess data quality. The next level defines data quality indicators (Table 2). Currently, 34 indicators are distinguished. They describe quality attributes of the data at the level of single data fields, data records, data elements, and data sets [37]. Figure 1 displays the hierarchical structure. Figure 2 illustrates the used nomenclature of terms for data structures within the framework.

\section{Integrity}

Integrity related analyses are guided by the question: Do all data comply with pre-specified structural and technical requirements? Addressing this as an independent step is necessary in any data quality assessment, because study data and metadata are often deficient. The three domains within this dimension address:

1) the structurally correct representation of data elements or data records within data sets (structural data set error), e.g. a mismatch of observed and expected number of data records;

2) the correspondence between multiple data sets (relational data set error), e.g. the appropriate integration of multiple study data sets; and

3) the correct representation of data values within data sets (value format error), e.g. a mismatch between the expected and observed data type.

Deficits at the integrity level may invalidate any findings at subsequent stages of data quality assessments and for any substantial scientific analyses. Assessments of metadata are confined to the integrity domain.

\section{Completeness}

Completeness related assessments are guided by the question: Are the expected data values available? Results provide knowledge about the frequency and distribution of missing data. Two domains within completeness treat missing data differently. Within the "crude missingness" 
Table 1 Data Quality Dimensions and Domains

\begin{tabular}{|c|c|c|c|}
\hline $\begin{array}{l}\text { Name Dimension } \\
\text { Domain }\end{array}$ & Definition & $\begin{array}{l}\text { Primary reference objects to } \\
\text { detect data quality issues }\end{array}$ & $\begin{array}{l}\text { Primary reporting } \\
\text { metrics of indicators }\end{array}$ \\
\hline Integrity & $\begin{array}{l}\text { The degree to which the data conforms to structural and } \\
\text { technical requirements. }\end{array}$ & & \\
\hline $\begin{array}{l}\text { Structural data set } \\
\text { error }\end{array}$ & $\begin{array}{l}\text { The observed structure of a data set differs from the expected } \\
\text { structure. }\end{array}$ & Data elements, data records & $\mathrm{N}$ \\
\hline $\begin{array}{l}\text { Relational data set } \\
\text { error }\end{array}$ & $\begin{array}{l}\text { The observed correspondence between different data sets } \\
\text { differs from the expected correspondence. }\end{array}$ & Data sets & $\mathrm{N}$ \\
\hline Value format error & $\begin{array}{l}\text { The technical representation of data values within a data set } \\
\text { does not conform to the expected representation. }\end{array}$ & Data fields & $N, \%$ \\
\hline Completeness & The degree to which expected data values are present. & & \\
\hline Crude missingness & $\begin{array}{l}\text { Metrics of missing data values that ignore the underlying } \\
\text { reasons for missing data. }\end{array}$ & Data fields & $\mathrm{N}, \%$ \\
\hline Qualified missingness & $\begin{array}{l}\text { Metrics of missing data values that use reasons underlying } \\
\text { missing data. }\end{array}$ & $\begin{array}{l}\text { Data fields, data elements, data } \\
\text { record }\end{array}$ & $\mathrm{N}, \%$ \\
\hline Consistency & Consistency & & \\
\hline $\begin{array}{l}\text { Range and value } \\
\text { violations }\end{array}$ & $\begin{array}{l}\text { Observed data values do not comply with admissible data } \\
\text { values or value ranges. }\end{array}$ & Data fields & $\mathrm{N}, \%$ \\
\hline Contradictions & $\begin{array}{l}\text { Observed data values appear in impossible or improbable } \\
\text { combinations. }\end{array}$ & Data fields & $\mathrm{N}, \%$ \\
\hline Accuracy & $\begin{array}{l}\text { The degree of agreement between observed and expected } \\
\text { distributions and associations. }\end{array}$ & & \\
\hline $\begin{array}{l}\text { Unexpected } \\
\text { distributions }\end{array}$ & $\begin{array}{l}\text { Observed distributional characteristics differ from expected } \\
\text { distributional characteristics. }\end{array}$ & Data elements, data records & $\begin{array}{l}\text { Diverse statistical } \\
\text { measures }^{\mathrm{a}}\end{array}$ \\
\hline $\begin{array}{l}\text { Unexpected } \\
\text { associations }\end{array}$ & Observed associations differ from expected associations. & Data elements, data records & $\begin{array}{l}\text { Diverse statistical } \\
\text { measures }^{a}\end{array}$ \\
\hline $\begin{array}{l}\text { Disagreement of } \\
\text { repeated } \\
\text { measurements }\end{array}$ & $\begin{array}{l}\text { Disagreement between repeated measurements of the same } \\
\text { or similar objects under specified conditions. }\end{array}$ & Data elements, data records & $\begin{array}{l}\text { Diverse statistical } \\
\text { measures }^{a}\end{array}$ \\
\hline
\end{tabular}

$\mathrm{N}$ : number of issues; \%: the percentage of issues relative to the number of assessed elements in a data structure

${ }^{a}$ A wide range of statistical metrics may apply such as location, scale or shape parameters, correlation coefficients, measures of agreement

domain, any specific reasons that underlie missing data are ignored because missing data are often improperly coded and meaningful indicators must nevertheless be computable. A common example is the provision of system-indicated missing values only such as NA in R. This impedes inferences on why data values are not available without context information. In contrast, "Qualified missingness" makes use of coded reasons for missing data such as refusals, met exclusion criteria or any other reason. The use of such missing codes enables the valid computation of non-response or refusal rates [38].

Missing data occur at different stages of a data collection. Reasons for participants not entering a study (1: unit missingness) may be different from those prompting a participant to leave the study after initial participation (2: longitudinal missingness, e.g. drop-out). Further restraints may impede the conduct of a segment of the study, such as a specific examination (3: segment missingness, e.g. taking part in an ultrasound examination). Within segments, there may be a failure to fully collect information (4: item missingness, e.g. refusal to respond to a question). Different sets of actionable information may result at each of these stages, both at the level of data quality management and statistical analyses. Analysing missing data at the stages 1 to 3 should forego the assessment of item missingness.

\section{Correctness: consistency and accuracy}

Correctness related analyses are guided by the question: Are data values free of errors? The first dimension, consistency comprises indicators that use Boolean type checks to identify inadmissible, impossible, or uncertain data values or combinations of data values. The domain range and value violations targets single data values that do not comply with allowed data values or value ranges [39]. The second domain, contradictions examines impossible or improbable combinations of multiple data values.

In contrast, indicators within the accuracy dimension use diverse statistical methods to identify unexpected data properties. Its first domain, unexpected distributions targets discrepancies between observed and expected distributional characteristics, e.g. the violation of an 
Table 2 Overview on Data Quality Indicators with Definitions

\begin{tabular}{|c|c|c|}
\hline ID & Name of indicator & Definition \\
\hline \multicolumn{3}{|l|}{ Integrity } \\
\hline $\begin{array}{l}\text { DQI- } \\
1001\end{array}$ & Unexpected data elements & The observed set of available data elements does not match the expected set. \\
\hline $\begin{array}{l}\text { DQI- } \\
1002\end{array}$ & Unexpected data records & The observed set of available data records does not match the expected set. \\
\hline $\begin{array}{l}\text { DQI- } \\
1003\end{array}$ & Duplicates & The same data elements or data records appear multiple times. \\
\hline $\begin{array}{l}\text { DQI- } \\
1004\end{array}$ & Data record mismatch & Data records from different data sets do not match as expected. \\
\hline $\begin{array}{l}\mathrm{DQI}- \\
1005\end{array}$ & Data element mismatch & Data elements from different data sets do not match as expected. \\
\hline $\begin{array}{l}\text { DQI- } \\
1006\end{array}$ & Data type mismatch & The observed data type does not match the expected data type. \\
\hline $\begin{array}{l}\text { DQI- } \\
1007\end{array}$ & Inhomogeneous value formats & The observed data values have inhomogeneous format across different data fields. \\
\hline $\begin{array}{l}\text { DQI- } \\
1008\end{array}$ & Uncertain missingness status & System indicated missing values (e.g. NA/./Null ...) appear where a qualified missing code is expected. \\
\hline \multicolumn{3}{|c|}{ Completeness } \\
\hline $\begin{array}{l}\text { DQI- } \\
2001\end{array}$ & Missing values & Data fields without a measurement value. \\
\hline $\begin{array}{l}\text { DQI- } \\
2002\end{array}$ & Non-response rate & The proportion of eligible observational units for which no information could be obtained. \\
\hline $\begin{array}{l}\text { DQI- } \\
2003\end{array}$ & Refusal rate & The proportion of eligible individuals who refuse to give the information sought. \\
\hline $\begin{array}{l}\text { DQI- } \\
2004\end{array}$ & Drop-out rate & The proportion of all participants who only partially complete the study and prematurely abandon it. \\
\hline $\begin{array}{l}\text { DQI- } \\
2005\end{array}$ & Missing due to specified reason & Information in a data collection that is missing due to a specified reason. \\
\hline \multicolumn{3}{|c|}{ Consistency } \\
\hline $\begin{array}{l}\text { DQI- } \\
3001\end{array}$ & Inadmissible numerical values & Observed numerical data values are not admissible according to the allowed ranges. \\
\hline $\begin{array}{l}\mathrm{DQI}- \\
3002\end{array}$ & Inadmissible time-date values & Observed time-date values are not admissible according to the allowed time and date ranges. \\
\hline $\begin{array}{l}\text { DQI- } \\
3003\end{array}$ & Inadmissible categorical values & Observed categorical data values are not admissible according to the allowed categories. \\
\hline $\begin{array}{l}\text { DQI- } \\
3004\end{array}$ & $\begin{array}{l}\text { Inadmissible standardized } \\
\text { vocabulary }\end{array}$ & Data values are not admissible according to the reference vocabulary. \\
\hline $\begin{array}{l}\text { DQI- } \\
3005\end{array}$ & Inadmissible precision & The precision of observed numerical data values does not match the expected precision. \\
\hline $\begin{array}{l}\text { DQI- } \\
3006\end{array}$ & Uncertain numerical values & Observed numerical values are uncertain or improbable because they are outside the expected ranges. \\
\hline $\begin{array}{l}\mathrm{DQ}- \\
3007\end{array}$ & Uncertain time-date values & Observed time-date values are uncertain or improbable because they are outside the expected ranges. \\
\hline $\begin{array}{l}\text { DQI- } \\
3008\end{array}$ & Logical contradictions & Different data values appear in logically impossible combinations. \\
\hline $\begin{array}{l}\text { DQI- } \\
3009\end{array}$ & Empirical contradictions & Different data values appear in combinations deemed impossible based on empirical reasoning. \\
\hline \multicolumn{3}{|c|}{ Accuracy } \\
\hline $\begin{array}{l}\text { DQI- } \\
4001\end{array}$ & Univariate outliers & Numerical data values deviate markedly from others in a univariate analysis. \\
\hline $\begin{array}{l}\text { DQI- } \\
4002\end{array}$ & Multivariate outliers & Numerical data values deviate markedly from others in a multivariate analysis. \\
\hline DQI- & Unexpected locations & Observed location parameters differ from expected location parameters. \\
\hline
\end{tabular}


Table 2 Overview on Data Quality Indicators with Definitions (Continued)

\begin{tabular}{|c|c|c|}
\hline ID & Name of indicator & Definition \\
\hline \multicolumn{3}{|l|}{4003} \\
\hline $\begin{array}{l}\text { DQI- } \\
4004\end{array}$ & Unexpected shape & The observed shape of a distribution differs from the expected shape. \\
\hline $\begin{array}{l}\text { DQI- } \\
4005\end{array}$ & Unexpected scale & Observed scale parameters differ from expected scale parameters. \\
\hline $\begin{array}{l}\text { DQI- } \\
4006\end{array}$ & Unexpected proportions & Observed proportions differ from expected proportions. \\
\hline $\begin{array}{l}\text { DQI- } \\
4007\end{array}$ & Unexpected association strength & The observed strength of an association deviates from the expected strength of the association. \\
\hline $\begin{array}{l}\text { DQI- } \\
4008\end{array}$ & $\begin{array}{l}\text { Unexpected association } \\
\text { direction }\end{array}$ & The observed direction of an association (e.g. negative, positive) deviates from the expected direction. \\
\hline $\begin{array}{l}\text { DQI- } \\
4009\end{array}$ & Unexpected association form & $\begin{array}{l}\text { The observed form of an association (e.g. linear, quadratic, exponential...) deviates from the expected } \\
\text { form. }\end{array}$ \\
\hline $\begin{array}{l}\text { DQI- } \\
4010\end{array}$ & Inter-Class reliability & $\begin{array}{l}\text { Differences between classes (e.g. examiners) when measuring the same or similar objects under } \\
\text { specified conditions. }\end{array}$ \\
\hline $\begin{array}{l}\text { DQI- } \\
4011\end{array}$ & Intra-Class reliability & $\begin{array}{l}\text { Differences within classes (e.g. examiners) when measuring the same or similar objects under specified } \\
\text { conditions. }\end{array}$ \\
\hline $\begin{array}{l}\text { DQI- } \\
4012\end{array}$ & $\begin{array}{l}\text { Disagreement with gold } \\
\text { standard }\end{array}$ & $\begin{array}{l}\text { Differences with a gold standard when measuring the same or similar objects under specified } \\
\text { conditions. }\end{array}$ \\
\hline
\end{tabular}

The term "expected" refers to a test criterion as annotated in metadata fields

expected normal distribution. The second domain, unexpected associations, assesses discrepancies between observed and expected associations. The third domain, disagreement of repeated measurements, targets the correspondence between repeated measurements of the same outcome, for example related to the precision of measurements, or the correspondence with gold standard measurements.

\section{Implementations}

Various methods exist to compute data quality indicators. For example, different approaches are available to calculate response rates [38] or to assess outliers [40, 41]. Implementations describe the actual computation of data quality indicators. They can be tailored to specific demands of data quality assessments and may summarize results from different indicators. Implementations may therefore be linked to any level of the data quality framework hierarchy, for example to provide overall estimates of data quality for some dimension. Changes of implementations do not constitute a modification of the data quality concept.

\section{Descriptors}

Results of data quality assessments should be available in machine-readable format. This is a necessary precondition for automated processing and subsequent aggregation of results. Yet, not all dataquality-related information may be expressed in a machine-readable format. For example, histograms or smoothed curves [42] may provide important insights in addition to a statistical test of some assumption about a distribution or association. However, the detection of a data quality issue based on graphs relies on the implicit knowledge of a person inspecting the results. Such output without a machine-readable metric is named a descriptor. All descriptive statistics are descriptors as well. To consider a sample mean as being problematic without an explicit rule-based assessment relies on implicit knowledge. A single descriptor may provide information for different indicators, as there are various possible interpretations. For example, a scatterplot may serve to identify outliers but also to detect unexpected associations and distributional properties.

\section{Data quality and process variables}

Data are collected over time, possibly at different sites, by different examiners using diverse methods. Ambient conditions may vary. Such sources of variability, coded as process variables [43], may affect measurements and result in data quality issues. Unexpected association of statistical parameters with process variables may constitute novel data quality problems and can be related to almost all data quality indicators. An example of high practical relevance are examiner effects (indicator: unexpected location, Table 2; implementation: examiner effects - margins, Table 3). Another example are time trends in the data. Such associations with process variables should routinely be targeted. 


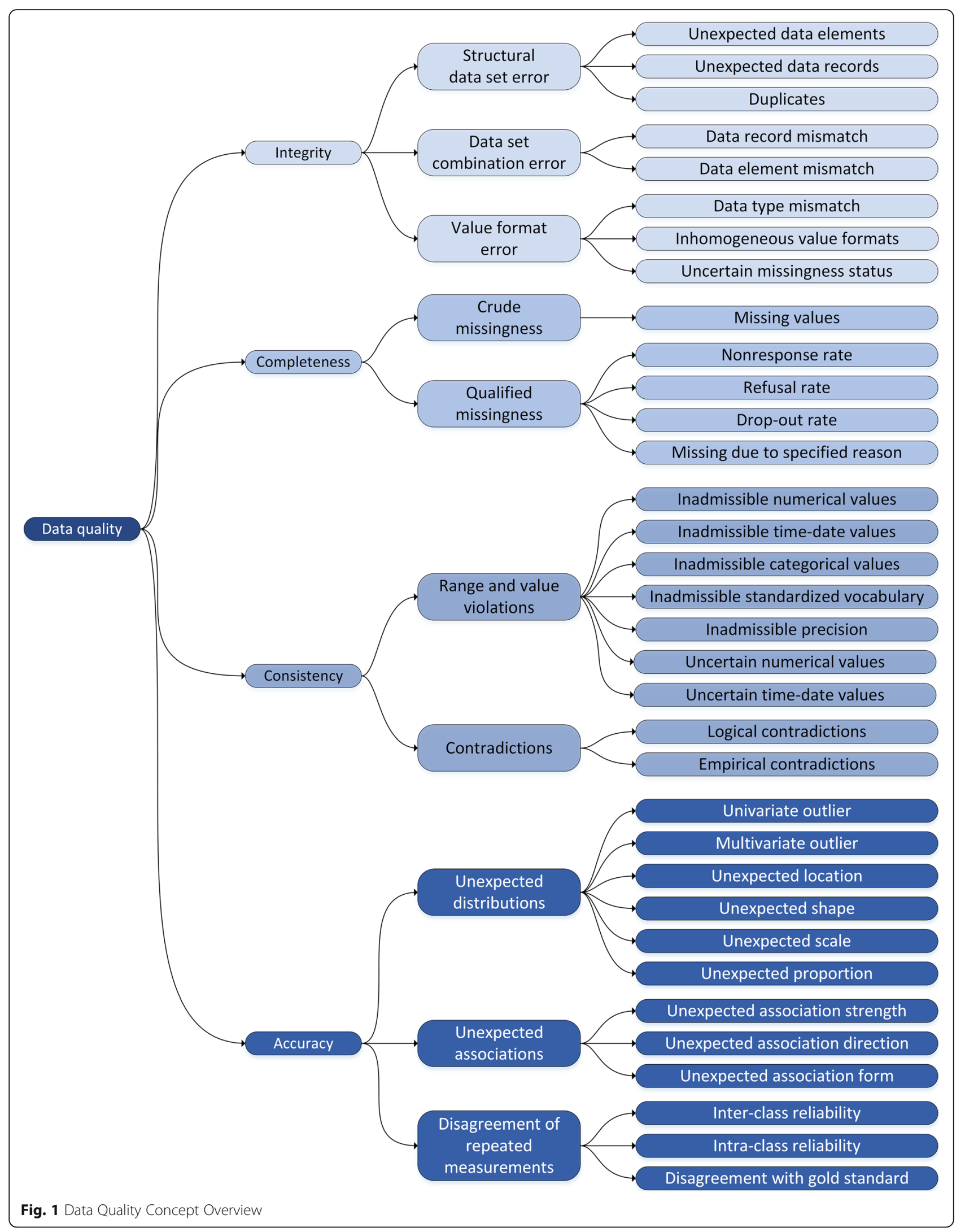




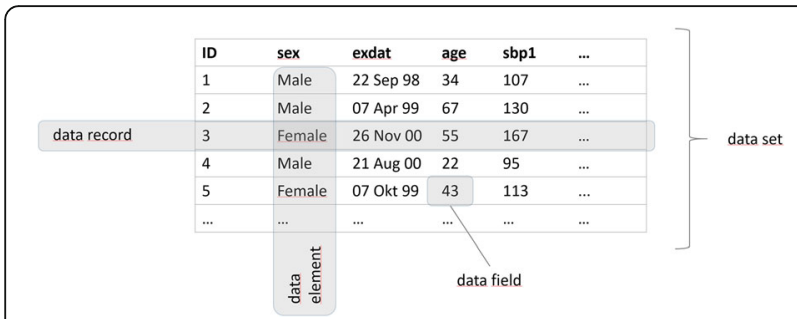

Fig. 2 Key terms related to data structures

\section{Using $\mathrm{R}$ and the data quality workflow}

Data quality can be assessed using the $\mathrm{R}$ package dataquieR. Table 3 provides an overview of the applied computational and statistical methods. The use of dataquieR can be twofold: (1) all-at-once without an in-depth specification of parameters using the function dq_report() to create complete default reports or (2) step-by-step allowing for a detailed data quality assessment in a sequential approach. The first option checks the availability of metadata and applies all appropriate functions to the specified study data. A flexdashboard [51] is then generated which summarizes the results by data quality dimensions and variables.

In contrast, the sequential approach allows for specific parameter settings, changes to the output, corrections and modification of the data, and stratification according to additional variables. Examples of the step-by-step approach are shown in Fig. 3 using SHIP data. For the sake of clarity, only five variables (data elements) have been selected for display. First, the applicability of implementations to each data element was checked. Apparently, the data type of "waist circumference" did not comply with the data type specified in the metadata (Fig. 3, panel 1 top-left). After resolving this issue further data quality checks were conducted. Item missingness has been tabulated to provide insights about different reasons for missing data at this level (Fig. 3, panel 2 bottom-left). Afterwards the consistency of the data was examined with respect to limit deviations (Fig. 3, panel 3 top-right). Among the different applications addressing accuracy, the adjusted margins function compares mean values across observers to address examiner effects while adjusting for a for a vector of covariates (Fig. 3, panel 4 bottom-right). A commented example is available in the tutorial section of the webpage.

\section{Discussion}

We provide a data quality framework for research data collections in observational health research, accompanied by software implementations in R. Data quality is addressed with regards to four core requirements: compliance with pre-specified structural and technical requirements (integrity), presence of data values (completeness), and absence of errors in the sense of, first, inadmissible data values, uncertain data values and contradictions (consistency) and second, unexpected distributions or associations (accuracy). To the best of our knowledge, this is the first data quality framework in the field that is accompanied by documented and freely available software code to compute indicators. A web page provides further guidance on all concepts and tools. The framework may promote harmonized data quality assessments and can be extended to accommodate other aspects of data quality and study types.

The framework was built from the perspective of "intrinsic data quality" [16] with requirements focussing on 1. processable data, 2. complete data, and 3. error-free data. The first dimension to target is integrity, as data quality assessments are a complex workflow where preconditions must be checked and reported first to safeguard the validity of subsequent results. Integrity in our framework resembles the conformance dimension in other approaches $[8,10]$, but focusses more narrowly structural requirements on data sets and data values. In practice, integrity checks often reveal recoverable issues. Additional data management processes may restore compliance with requirements, for example, by adding missing data structures.

In line with other approaches [6-8], completeness and correctness are the other main aspects of data quality. Both have been defined as core data quality constructs with regard to EHR data in the framework of Weiskopf et al. [9]. The stronger notion of correctness was preferred over plausibility $[8,10]$ because the data generation in observational health research data collections is largely under the control of the researchers. This implies strong options to address errors during data collections and thereafter. We did not include the third core dimension by Weiskopf et al. [9], currency, which denotes whether "a value is representative of the clinically relevant time". This aspect is considered to be of lesser importance in a research data collection from an intrinsic perspective.

Despite overlap with the TMF guideline [11, 14], Table 4, our data quality framework differs in several regards. The TMF-guideline focuses on registries while our framework focuses data collected for research purposes. Our framework is organized hierarchically, whereas there is no comparable structure in the TMFguideline. TMF indicators correspond to different elements of our approach, ranging from data quality dimensions to implementations (Table 4). We cover all of the indicators classified as important [29] in the evaluation of the TMF-guideline with two exceptions: Compliance with operating procedures (TMF-1047) has not been included because information in standard operating procedures or study protocols is not available in an appropriate format for automated assessments. 
Table 3 Example R-Functions and their Links to The Data Quality Framework

\begin{tabular}{|c|c|c|}
\hline $\begin{array}{l}\text { R-function } \\
\text { name }\end{array}$ & Implementations within the function & Linked with the following indicators \\
\hline $\begin{array}{l}\text { pro_ } \\
\text { applicability } \\
\text { matrix() }\end{array}$ & $\begin{array}{l}\text { Checks the correspondence of study data with the metadata and } \\
\text { accessibility to files. Each study data variable is examined regarding the } \\
\text { data type and cross-checked with the specified data type in the } \\
\text { metadata. }\end{array}$ & $\begin{array}{l}\text { Unexpected data elements; } \\
\text { data type mismatch }\end{array}$ \\
\hline $\begin{array}{l}\text { com_unit__ } \\
\text { missingness() }\end{array}$ & $\begin{array}{l}\text { Evaluates on the level of entire observational units whether all } \\
\text { measurements are missing. }\end{array}$ & Missing measurements (Unit level) \\
\hline $\begin{array}{l}\text { com_- } \\
\text { segment_- } \\
\text { missingness() }\end{array}$ & $\begin{array}{l}\text { Evaluates whether all associated measurements at the level of study } \\
\text { segments (e.g. single examinations or instruments) are missing for an } \\
\text { observational unit. A pattern plot is provided as a descriptor. }\end{array}$ & Missing measurements (Segment level); \\
\hline $\begin{array}{l}\text { com_item_- } \\
\text { missingness() }\end{array}$ & $\begin{array}{l}\text { Examines for each variable of the study data the amount and type of } \\
\text { missing data according to specified missing/jump codes, including a }\end{array}$ & $\begin{array}{l}\text { Missing measurements (Item level); specific missingness; } \\
\text { uncertain missingness status }\end{array}$ \\
\hline
\end{tabular}

con_limit__ Assesses limit deviations, with regards to inadmissible and improbable deviations() values and counts deviations above/below the specified thresholds. Limits may comprise hard limits to identify inadmissible values, soft limits to identify improbable values, and detection limits which refer to a censoring based on the properties of the measurement devices used.

con__ Compares the match of single data values with admissible categories, inadmissible_ summarizes observed vs. expected data values and counts the violations. categorical)

con_ Compares two data values of the same observational unit by using one contradictions() of 16 logical comparisons. Counts the number of contradictions.

$\begin{array}{ll}\text { acc_- } & \text { Creates distributional plots (bar or histogram) for numerical } \\ \text { distributions() } & \text { measurements (float, integer). If a grouping variable is provided, stratified }\end{array}$ distributions() measurements (float, integer). If a grouping variable is provided, stratified
empirical cumulative distribution functions (ecdf) are plotted as well [20].
acc univariate Computes distributional characteristics of numerical measurements (e.g. outlier() mean, standard deviation, skewness) and applies four different rules to identify univariate outliers, e.g. Tukey, Hubert, and six sigma [44-46]. Counts the number of outliers and indicates the direction (low/high).

acc__ Computes the Mahalanobis distance of at least two variables and counts multivariate_ _ the number of extreme measurements. In a heuristic approach outlier outlier() - identification is based on applying simple univariate rules [44-46] on the Mahalanobis distance to reduce computational costs.

acc_shape_or_ Tests the observed distribution of measurements against predefined scale() distributional assumption (normal, gamma, uniform). Deviations from expected distributions are visualized using the idea of rootograms [44, 47].

acc_end__ Computes preferences of manually collected data, i.e. the preference of digits() end digits. The functions assume a uniform distribution of end digits and applies a rootogram-like visualization [44, 47].

acc_margins) Compares the marginal distribution of different classes (e.g. examiners, devices) using measurements adjusted for covariates (e.g. age, sex). Adjusted linear models, logistic regression or poisson-regression are used to model marginal means of continuous measurements, binary, and count data [48].

acc_varcomp() Computes the variance proportion explained by different classes (e.g. examiners, devices) in relation to the overall variance of the measurement. Depending on the data ANOVA or mixed effects models are applied $[49,50]$

acc_loess() Computes and displays as a descriptor loess-smoothed trends of measurements across different classes over time. The raw measurements can be adjusted for covariates such as age or sex and the resulting residuals are

Inadmissible numerical values; inadmissible time-date values; uncertain numerical values; uncertain time-date values

Inadmissible categorical values

Logical contradictions; empirical contradictions

Indicators within the unexpected distributions domain

Univariate outliers

Multivariate outliers

Unexpected shape parameter; unexpected scale parameter

Unexpected shape

Unexpected location; unexpected proportion

Unexpected location

Indicators within the unexpected distributions domain, foremost unexpected location; unexpected proportion smoothed over time using LOESS [42].

Representativeness (TMF-1048) can be formally targeted using indicators within the unexpected distributions domain to check observed sample properties against known population characteristics. It is however a matter of context-knowledge to interpret findings as a result of selection bias instead of measurement error. As such, representativeness is a contextual rather than an intrinsic aspect of data quality. 


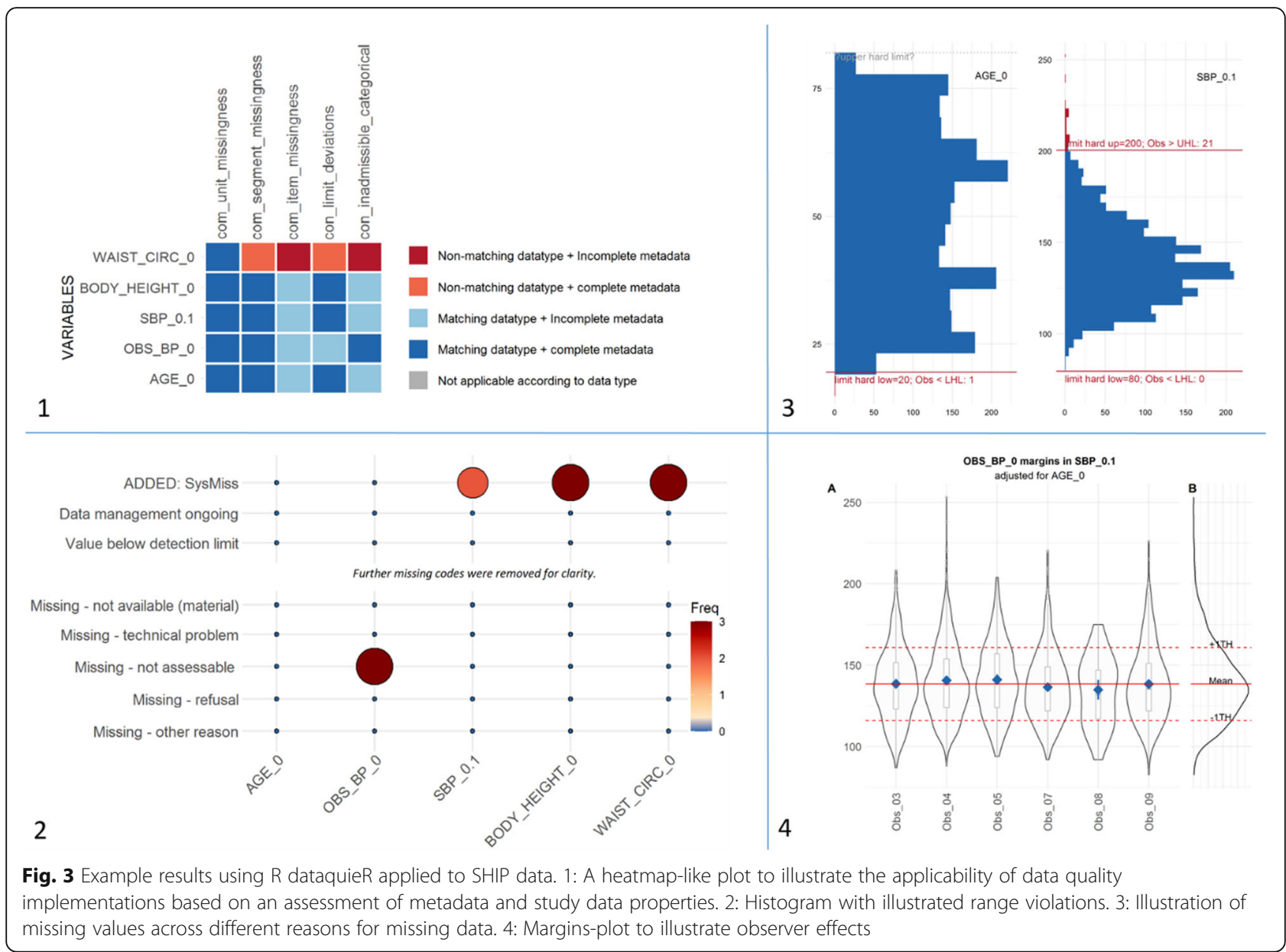

\section{Computation of data quality indicators}

The necessity to develop software for data quality assessments has previously been acknowledged [8, 9]. Providing not only a theoretical framework but also the code to analyse data quality is important to facilitate homogeneous and transparent assessments across studies. This is also of relevance for the implementation of harmonized data quality assessments within complex research data infrastructures such as euCanSHare [52] or NFDI4Health, a federated research data infrastructure for personal health data [53]. Our implementations differ from most other available program codes [18-24] in that they are attached to a formal framework. To ensure the robustness of implementation, dozens of utility functions support their appropriate application in the background. Standards for the setup of metadata were defined to enable automated data quality checks [43] as well as for the programmed $\mathrm{R}$ routines to avoid heterogeneous programming code. This will facilitate extensions by other scientists. Further software implementations within the program Stata and a Java web-application [54] are currently being programmed.

\section{Data quality assessments in research}

Data quality assessments must generate actionable information. While a study is carried out, the main aim is to detect and mitigate errors. After the end of a data collection, data quality assessments can be conceived as a specific aspect of initial data analysis [3], which aims "to provide reliable knowledge about the data to enable responsible statistical analyses and interpretation". As such, the presented work also provides a framework for structuring initial data analysis.

Data quality assessments may be conducted locally at the sites of the respective data holders by using the software implementations above. Further transparency is possible if data quality related metadata is stored centrally in widely used metadata repositories. One example are the Opal and Mica [55] tools which are used, among others, in euCanSHare [52], Maelstrom [56], and NFDI4Health [53]. Another example is the Medical Data Models Portal, a meta-data registry for sharing and reusing medical forms [57]. Developments to host the necessary metadata in metadata repositories are currently ongoing. 
Table 4 Correspondence of TMF data quality indicators with the current data quality framework

\begin{tabular}{|c|c|c|c|}
\hline $\begin{array}{l}\text { TMFI } \\
\text { D }\end{array}$ & TMF name & $\begin{array}{l}\text { Related in current framework } \\
\text { to concept }\end{array}$ & $\begin{array}{l}\text { Description of element type/ implementation in current } \\
\text { framework }\end{array}$ \\
\hline $\begin{array}{l}\text { TMF- } \\
1001\end{array}$ & Agreement with previous values & $\begin{array}{l}\text { Disagreement of repeated } \\
\text { measurements }\end{array}$ & Domain \\
\hline $\begin{array}{l}\text { TMF- } \\
1003\end{array}$ & Consistency & Contradictions & Domain \\
\hline $\begin{array}{l}\text { TMF- } \\
1004\end{array}$ & Certain contradiction/error & Certain contradictions & Indicator \\
\hline $\begin{array}{l}\text { TMF- } \\
1005\end{array}$ & Possible contradiction/warning & Uncertain contradictions & Indicator \\
\hline $\begin{array}{l}\text { TMF- } \\
1006 \\
\text { TMF- } \\
1009 \\
\text { TMF- } \\
1010 \\
\text { TMF- } \\
1011 \\
\text { TMF- } \\
1052\end{array}$ & $\begin{array}{l}\text { Distribution of values } \\
\text { Distribution of parameters recorded by the } \\
\text { investigator } \\
\text { Distribution of parameters recorded by the } \\
\text { device } \\
\text { Distribution of findings recorded by a } \\
\text { medical reader } \\
\text { Distribution of parameters between study } \\
\text { sites }\end{array}$ & $\begin{array}{l}\text { Unexpected location parameter } \\
\text { Unexpected shape parameter } \\
\text { Unexpected scale parameter } \\
\text { Unexpected proportion }\end{array}$ & $\begin{array}{l}\text { Indicator but TMF differentiates by the influencing factor } \\
\text { while the current framework distinguishes by the statistical } \\
\text { aspect. }\end{array}$ \\
\hline $\begin{array}{l}\text { TMF- } \\
1012\end{array}$ & Missing modules & Unexpected data elements & $\begin{array}{l}\text { An implementation that identifies missing modules within } \\
\text { the indicator unexpected data elements }\end{array}$ \\
\hline $\begin{array}{l}\text { TMF- } \\
1013\end{array}$ & Missing values in data elements & Missing values & Indicator \\
\hline $\begin{array}{l}\text { TMF- } \\
1014\end{array}$ & Missing values in mandatory data elements & Missing values & $\begin{array}{l}\text { An implementation that identifies mandatory data elements } \\
\text { within the indicator missing values }\end{array}$ \\
\hline $\begin{array}{l}\text { TMF- } \\
1016\end{array}$ & Data elements with value unknown etc. & Missing due to specified reason & $\begin{array}{l}\text { Indicator (TMF targets a specific reason for missing value: } \\
\text { unknown values) }\end{array}$ \\
\hline $\begin{array}{l}\text { TMF- } \\
1018\end{array}$ & Outliers (continuous data elements) & Univariate outliers & Indicator \\
\hline $\begin{array}{l}\text { TMF- } \\
1019\end{array}$ & Values that exceed the measurability limits & Inadmissible numerical values & Implementation within inadmissible numerical values \\
\hline $\begin{array}{l}\text { TMF- } \\
1021\end{array}$ & Illegal values of qualitative data elements & Inadmissible categorical values & Indicator \\
\hline $\begin{array}{l}\text { TMF- } \\
1022\end{array}$ & $\begin{array}{l}\text { Illegal values of qualitative data elements } \\
\text { used for the coding of missings }\end{array}$ & Inadmissible categorical values & $\begin{array}{l}\text { An implementation that identifies inadmissible coding of } \\
\text { missing modules within the indicator inadmissible } \\
\text { categorical values }\end{array}$ \\
\hline $\begin{array}{l}\text { TMF- } \\
1023\end{array}$ & $\begin{array}{l}\text { Illegal values used for the coding of missing } \\
\text { modules }\end{array}$ & Inadmissible categorical values & $\begin{array}{l}\text { An implementation that identifies inadmissible coding of } \\
\text { missing values within the indicator inadmissible categorical } \\
\text { values }\end{array}$ \\
\hline $\begin{array}{l}\text { TMF- } \\
1024\end{array}$ & $\begin{array}{l}\text { Illegal values of qualitative data elements } \\
\text { used for the coding of results exceeding } \\
\text { measurability limits }\end{array}$ & Inadmissible categorical values & $\begin{array}{l}\text { An implementation that identifies data elements with codes } \\
\text { related to measurability limits within the indicator } \\
\text { inadmissible categorical values }\end{array}$ \\
\hline $\begin{array}{l}\text { TMF- } \\
1029\end{array}$ & Duplicates & Duplicates & Indicator \\
\hline $\begin{array}{l}\text { TMF- } \\
1030\end{array}$ & Recruitment rate & Nonresponse rate & $\begin{array}{l}\text { Indicator, the current framework uses the inverse. The link } \\
\text { between both depends on the definition of recruitment and } \\
\text { nonresponse rates }\end{array}$ \\
\hline $\begin{array}{l}\text { TMF- } \\
1031 \\
\text { TMF- } \\
1032\end{array}$ & $\begin{array}{l}\text { Refusal rate of investigations } \\
\text { Refusal rate of modules }\end{array}$ & Refusal rate & $\begin{array}{l}\text { Indicator with implementations at the level of examination } \\
\text { modules or the entire study }\end{array}$ \\
\hline $\begin{array}{l}\text { TMF- } \\
1034\end{array}$ & Drop-out-rate & Drop-out rate & Indicator \\
\hline $\begin{array}{l}\text { TMF- } \\
1042\end{array}$ & Observational units with follow-up & $\begin{array}{l}\text { Non-response rate (inverse at } \\
\text { unit level, depending on } \\
\text { implementation form) }\end{array}$ & Indicator \\
\hline TMF- & Accuracy & Accuracy & Dimension \\
\hline
\end{tabular}


Table 4 Correspondence of TMF data quality indicators with the current data quality framework (Continued)

\begin{tabular}{lll}
\hline $\begin{array}{l}\text { TMFI TMF name } \\
\text { D }\end{array}$ & $\begin{array}{l}\text { Related in current framework } \\
\text { to concept }\end{array}$ & $\begin{array}{l}\text { Description of element type/ implementation in current } \\
\text { framework }\end{array}$ \\
\hline 1043 & & Dimension \\
TMF- Completeness & Completeness & \\
1046 & &
\end{tabular}

1) Included are TMF-indicators that have been classified as being at least important based on an empirical evaluation [29]. Two indicators with an important rating have not been included, "Compliance with procedural rule" (TMF-1047) and "Representativeness" (TMF-1048), as described in discussion

Another aspect are intelligible metrics to communicate information about the achieved data quality, such as visual alerts. This has been implemented in the SHIPproject. Related standards could facilitate communication between scientists to leverage a common understanding of data quality. This goal is also pursued by the Data Nutrition Project [58]. Yet, the latter takes a different methodological approach and focusses primarily on the intended use of data, thus emphasizing contextual data quality [16], whereas we emphasize intrinsic data quality. Future extensions of our framework to cover contextual data quality may increase overlap. Vice versa, structural aspects of the framework and suggested workflow may be of relevance to guide other approaches.

Another goal is to improve the scientific reporting of studies and the further elaboration of guidance documents to cover aspects of data quality more extensively, such as for example by the EQUATOR (Enhancing the QUAlity and Transparency Of health Research) network [59] or the STRATOS (STRengthening Analytical Thinking for Observational Studies) initiative [60]. Furthermore, many funding bodies require data management plans but no system exists for the handling or reporting of data quality. Standardized data quality reports may accompany both, final reports and scientific papers to provide transparent insights into data properties and study success. As a necessary precondition for harmonized data quality assessments, the improved management of metadata would contribute to a better compliance with FAIR (Findable, Accessible, Interoperable and Reusable) data principles [61].

\section{Limitations and outlook}

The presented data quality framework does not cover all aspects of "fitness for use" (ISO 8000) as contextual aspects have not been taken into account. For example, a single missing data value due to a technical error may trigger corrective actions during data collection but may not affect statistical analyses. Thresholds for critical amounts of missing data depend on the methods and aims of a statistical analysis plan [62]. Even without data quality issues at the intrinsic level some data set may prove unfit for the study of a research question because of issues such as an insufficient number of events if the main outcome is a time-to-event variable.
While the defined set of indicators suffices to address a wide range of data quality issues further expansions will be necessary. For example, speaking of nonresponse rate in studies without a clearly defined sampling frame may not be appropriate and additional indicators need to be added [38]. The framework currently also does not address specific demands arising from special data sources such as omics or medical imaging.

Indicators make no assumptions about the underlying reasons for data quality issues. It is up to the scientist or data manager to make causal decisions, for example on the presence of some type of bias [63]. This in turn relies on the study design being well-documented and the study being conducted accordingly $[64,65]$.

We defined indicators that are statistically computable in an automated workflow, using a set of study data and metadata. Therefore, we did not address approaches of source data verification. To avoid lengthy computational times, in some cases heuristic statistical methods have been favoured over ones that are more sophisticated.

The functionality of $\mathrm{R}$ code is supported by versatile and numerous utility function to mitigate user errors. Nonetheless, this code relies on the existence of sufficient metadata and metadata itself may constitute a gateway for data quality issues. Any user must comprehend the framework and the conventions underlying the definition of metadata. Because the handling of study data varies greatly across studies, interoperability issues may arise, and the provision of interfaces to facilitate data transfer will be an important future extension of our work. Therefore, an alignment of data quality related metadata with standards for information exchange such as HL7 FHIR [66] and common data models to enable data quality assessments without additional efforts in a harmonized fashion across data sets is a main objective $[53,67]$.

We have sketched application scenarios of data quality assessments during the research data life cycle, yet quantitative approaches to data quality are also of relevance in other areas of life. For example, data quality monitoring during study conduct shares structural similarities with quality improvement related activities in a hospital setting. Benchmarking is of relevance for production processes in industrial settings. Sustainable decisionmaking and innovation rests on the availability of data 
with adequate quality properties. Aspects of the outlined framework may be useful whenever data is collected for such purposes in a designed and controlled fashion. Yet, each application scenario has its specific requirements that likely require adaptions and extensions of this framework as well as the related software implementations.

\section{Conclusions}

A data quality framework for research data collections in observational health research is provided with software implementations in the programming language $R$. The framework covers four core aspects of data quality: compliance with pre-specified formats and structures (integrity), the presence of data values (completeness), and errors in the data values in the sense of inadmissible or uncertain data values as well as contradictions (consistency) and unexpected distributions or associations (accuracy). $\mathrm{R}$ functions facilitate harmonized data quality assessments within and across studies in pursue of transparent and reproducible research. Applications of the framework and software implementations are not limited to research.

\begin{abstract}
Abbreviations
ANOVA: Analysis of variance; DQ: Data quality; DQI: Data quality indicator; ecdf: Empirical cumulative distribution functions; EHR: Electronic health records; EQUATOR: Enhancing the QUAlity and Transparency Of health Research; exdat: Examination date; FAIR: Findable, Accessible, Interoperable and Reusable; FHIR: Fast Healthcare Interoperability Resources; HL7: Health Level 7; IDA: Initial data analysis; ISO: International standards organization; LOESS: Locally estimated scatterplot smoothing; NA: Not applicable; sbp: Systolic blood pressure; SHIP: Study of Health in Pomerania; STRA TOS: STRengthening Analytical Thinking for Observational Studies; TMF: Technology, Methods, and Infrastructure for Networked Medical Research; TMFID: TMF guideline identifier
\end{abstract}

\section{Acknowledgements}

We thank the TMF e.V., an umbrella organization for networked medical research in Germany, for providing infrastructure to facilitate interdisciplinary exchange on our developments and participants of meetings for their comments.

\section{Authors' contributions}

COS: design of the research project, manuscript drafting and concept development, support of software development / web design, evaluation of TMF guideline; AR: manuscript drafting, software development, concept development, web design; StS: software development; website design; manuscript revision; CE, ACR, JS, SD, BS: evaluation of TMF guideline, input regarding epi study data quality assessments; feedback/revision on concept and tools; critical revision of manuscript; WS, MH: feedback on concept and tools with a focus on statistics, initial data analysis; critical revision of manuscript. All authors have approved the manuscript.

\section{Authors' information}

Not applicable.

\section{Funding}

This work was supported by the German Research Foundation (DFG: SCHM 2744/3-1, JO 170/10-1, KU 3111/2-1, LO 342/13-1, PI 345/11-1, STA 454/171, SCHM 2744/9-1, SA 580/10-1), by the TMF grant V114-01 M, and by the European Union's Horizon 2020 research and innovation programme under grant agreement No 825903 (euCanSHare project). Open Access funding enabled and organized by Projekt DEAL.

\section{Availability of data and materials}

The datasets generated and/or analyzed during the current study are available in the dataquieR repository on gitlab, https://gitlab.com/libreumg/ dataquier/-/tree/master/inst/extdata

\section{Declarations}

Ethics approval and consent to participate

Not applicable.

\section{Consent for publication}

All authors have approved the manuscript for publication.

\section{Competing interests}

The authors declare that they have no competing interests.

\section{Author details}

${ }^{1}$ Institute for Community Medicine, Department SHIP-KEF, University Medicine Greifswald, Greifswald, Germany. ${ }^{2}$ Institute for Medical Informatics, Statistics, and Epidemiology, University of Leipzig, Leipzig, Germany. ${ }^{3}$ Leibniz Institute for Prevention Research and Epidemiology - BIPS, Bremen, Germany. ${ }^{4}$ Institute for Medical Informatics, Biometry and Epidemiology (IMIBE), Faculty of Medicine, University of Duisburg-Essen, Duisburg, Germany. ${ }^{5}$ Robert Koch Institute, Department of Epidemiology and Health Monitoring, Berlin, Germany. ${ }^{6}$ Department of Statistics and Probability, Michigan State University, East Lansing, MI, USA. ${ }^{7}$ Institute of Medical Biometry and Statistics, Faculty of Medicine and Medical Center, University of Freiburg, Freiburg, Germany.

Received: 1 December 2020 Accepted: 12 March 2021

Published online: 02 April 2021

\section{References}

1. Houston ML, Yu AP, Martin DA, Probst DY. Defining and developing a generic framework for monitoring data quality in clinical research. AMIA Annu Symp Proc. 2018;2018:1300-9.

2. Fortier I, Burton PR, Robson PJ, Ferretti V, Little J, L'Heureux F, et al. Quality, quantity and harmony: the DataSHaPER approach to integrating data across bioclinical studies. Int J Epidemiol. 2010;39(5):1383-93. https://doi.org/10.1 093/ije/dyq139.

3. Huebner M, Le Cessie S, Schmidt CO, Vach W. A contemporary conceptual framework for initial data analysis. Observ Stud. 2018;4:71-192.

4. Maelstrom guidelines. https://www.maelstrom-research.org/page/ma elstrom-guidelines. Accessed 25 Mar 2021

5. Arts DG, De Keizer NF, Scheffer GJ. Defining and improving data quality in medical registries: a literature review, case study, and generic framework. J Am Med Inform Assoc. 2002;9(6):600-11. https://doi.org/1 0.1197/jamia.M1087.

6. Stausberg J, Nasseh D, Nonnemacher M. Measuring data quality: a review of the literature between 2005 and 2013. Stud Health Technol Inform. 2015; 210:712-6.

7. Weiskopf NG, Weng C. Methods and dimensions of electronic health record data quality assessment: enabling reuse for clinical research. J Am Med Inform Assoc. 2013;20(1):144-51. https://doi.org/10.1136/amiajnl-2011000681.

8. Lee K, Weiskopf N, Pathak J. A framework for data quality assessment in clinical research datasets. AMIA Annu Symp Proc. 2017;2017:1080-9.

9. Weiskopf NG, Bakken S, Hripcsak G, Weng C. A Data Quality Assessment Guideline for Electronic Health Record Data Reuse. EGEMS (Wash DC). 2017; $5(1): 14$.

10. Kahn MG, Callahan TJ, Barnard J, Bauck AE, Brown J, Davidson BN, et al. A Harmonized Data Quality Assessment Terminology and Framework for the Secondary Use of Electronic Health Record Data. EGEMS (Wash DC). 2016; 4(1):1244.

11. Nonnemacher M, Nasseh D, Stausberg J. Datenqualität in der medizinischen Forschung: Leitlinie zum Adaptiven Datenmanagement in Kohortenstudien und Registern. Berlin: TMF e.V; 2014. https://doi.org/10.32745/9783954663 743.

12. European Centre for Disease Prevention and Control. Data quality monitoring and surveillance system evaluation - A handbook of methods and applications. Stockholm: ECDC; 2014. 
13. Warwick W, Johnsona S, Bonda J, Fletchera G, Kanellakisa P. A framework to assess healthcare data quality. Eur J Soc Behav Sci. 2015;13(2):1730-5. https://doi.org/10.15405/ejsbs.156.

14. Stausberg J, Bauer U, Nasseh D, Pritzkuleit R, Schmidt CO, Schrader T, et al. Indicators of data quality: review and requirements from the perspective of networked medical research. MIBE. 2019;15(1):1-8.

15. Nonnemacher M, Weiland D, Stausberg J. Leitlinie zum adaptiven Management von Datenqualität in Kohortenstudien und Registern Berlin: Medizinisch Wissenschaftliche Verlagsgeselschaft; 2007.

16. Wang RY, Strong DM. Beyond accuracy: what data quality means to data consumers. J Manag Inf Syst. 1996;12(4):5-33. https://doi.org/10.1080/ 07421222.1996 .11518099$.

17. Keller S, Korkmaz G, Orr M, Schroeder A, Shipp S. The evolution of data quality: understanding the Transdisciplinary origins of data quality concepts and approaches. Annual Review of Statistics and Its Application. 2017;4(1): 85-108. https://doi.org/10.1146/annurev-statistics-060116-054114.

18. Kandel S, Parikh R, Paepcke A, Hellerstein JM, Heer J. Profiler: Integrated statistical analysis and visualization for data quality assessment. In: Proceedings of the International Working Conference on Advanced Visual Interfaces: 2012: ACM; 2012. p. 547-54.

19. Golling $T$, Hayward $H$, Onyisi $P$, Stelzer $H$, Waller $P$. The ATLAS data quality defect database system. The European Physical Journal C. 2012;72(4):1960. https://doi.org/10.1140/epjc/s10052-012-1960-y.

20. Dasu T, Johnson T. Exploratory data mining and data cleaning, vol. 479: Wiley; 2003.

21. De Jonge $E$, Van Der Loo M. An introduction to data cleaning with R: statistics Netherlands Heerlen; 2013.

22. Templ M, Filzmoser P. Visualization of missing values using the R-package VIM. Reserach report cs-2008-1, Department of Statistics and Probability Therory, Vienna University of Technology; 2008.

23. Comtois D. R package 'summarytools'; 2016. https://CRAN.R-project.org/pa ckage $=$ summarytools,

24. Waljee AK, Mukherjee A, Singal AG, Zhang Y, Warren J, Balis U, et al. Comparison of imputation methods for missing laboratory data in medicine. BMJ Open. 2013;3(8):e002847. https://doi.org/10.1136/bmjopen-2013-002847.

25. Observational Health Data Sciences and Informatics (OHDSI). Data quality dashboard. https://data.ohdsi.org/DataQualityDashboard/. Accessed 25 Mar 2021.

26. Kapsner LA, Kampf MO, Seuchter SA, Kamdje-Wabo G, Gradinger T, Ganslandt T, et al. Moving towards an EHR data quality framework: the MIRACUM approach. Stud Health Technol Inform. 2019;267:247-53. https:// doi.org/10.3233/SHTI190834.

27. Stausberg J, Bauer U, Nasseh D, Pritzkuleit R, Schmidt CO, Schrader T. Nonnemacher M: Indicators of data quality: review and requirements from the perspective of networked medical research. MIBE. 2019;15(1). (ePub). https://doi.org/10.3205/mibe000199.

28. Chen H, Hailey D, Wang N, Yu P. A review of data quality assessment methods for public health information systems. Int J Environ Res Public Health. 2014;11(5):5170-207. https://doi.org/10.3390/ijerph110505170.

29. Schmidt C, Richter A, Enzenbach C, Pohlabeln H, Meisinger C, Wellmann J, et al. Assessment of a data quality guideline by representatives of German epidemiologic cohort studies. GMS Med Inform Biom Epidemiol. 2019;15(1). (ePub). https://doi.org/10.3205/mibe000203.

30. Richter A, Schmidt CO, Struckmann S. dataquieR: Data Quality in Epidemiological Research; 2021. https://CRAN.R-project.org/package=data quieR.

31. Development $\mathrm{R}$, Core team. $\mathrm{R}$ : a language and environment for statistical computing. Vienna: R Foundation for Statistical Computing; 2020.

32. Wickham H. Advanced r: chapman and hall/CRC; 2014. https://doi.org/10.12 01/b17487.

33. Volzke H, Alte D, Schmidt CO, Radke D, Lorbeer R, Friedrich N, et al. Cohort profile: the study of health in Pomerania. Int J Epidemiol. 2011;40(2):294307. https://doi.org/10.1093/ije/dyp394.

34. Loeffler M, Engel C, Ahnert P, Alfermann D, Arelin K, Baber R, et al. The LIFEadult-study: objectives and design of a population-based cohort study with 10,000 deeply phenotyped adults in Germany. BMC Public Health. 2015; 15(1):1-14.

35. Ahrens W, Siani A, Adan R, De Henauw S, Eiben G, Gwozdz W, et al. Cohort Profile: The transition from childhood to adolescence in European childrenhow I. Family extends the IDEFICS cohort. Int J Epidemiol. 2017:46(5):1394$1395 j$.
36. Standards and Tools for Data Quality Assessment in Epidemiologica Studies. https://dfg-qa.ship-med.uni-greifswald.de/. Accessed 25 Mar 2021.

37. Patrick RL. Data quality indicators and their use in data base systems. Rand Corp: Santa Monica; 1980.

38. The American Association for Public Opinion Research. Standard Definitions: Final Dispositions of Case Codes and Outcome Rates for Surveys. 9th ed; 2016.

39. Brown J, Kahn M, Toh S. Data quality assessment for comparative effectiveness research in distributed data networks. Med Care. 2013:51(8 0 3):S22.

40. Aguinis $\mathrm{H}$, Gottfredson RK, Joo H. Best-practice recommendations for defining, identifying, and handling outliers. Organ Res Methods. 2013;16(2): 270-301. https://doi.org/10.1177/1094428112470848.

41. Sunderland KM, Beaton D, Fraser J, Kwan D, McLaughlin PM, Montero-Odasso $\mathrm{M}$, et al. The utility of multivariate outlier detection techniques for data quality evaluation in large studies: an application within the ONDRI project. BMC Med Res Methodol. 2019;19(1):102. https://doi.org/10.1186/s12874-019-0737-5.

42. Cleveland WS, Devlin SJ. Locally weighted regression: an approach to regression analysis by local fitting. J Am Stat Assoc. 1988;83(403):596-610. https://doi.org/10.1080/01621459.1988.10478639.

43. Richter A, Schössow J, Werner A, Schauer B, Radke D, Henke J, et al. Data quality monitoring in clinical and observational epidemiologic studies: the role of metadata and process information. MIBE. 2019;15(1). (ePub). https:// doi.org/10.3205/mibe000202

44. Tukey JW. Exploratory data analysis. Reading, Mass: Addison-Wesley Pub. Co. 1977.

45. Hubert M, Vandervieren E. An adjusted boxplot for skewed distributions Comput Stat Data Anal. 2008;52(12):5186-201. https://doi.org/10.1016/j. csda.2007.11.008

46. Sedlack JD. The utilization of six sigma and statistical process control techniques in surgical quality improvement. J Healthc Qual. 2010;32(6):1826. https://doi.org/10.1111/j.1945-1474.2010.00102.x.

47. Kleiber C, Zeileis A. Visualizing count data regressions using rootograms. Am Stat. 2016;70(3):296-303. https://doi.org/10.1080/00031305.2016.1173590.

48. Lenth RV. Least-squares means: the R package Ismeans. J Stat Softw. 2016; 69(1):1-33.

49. Verbeke G. Linear mixed models for longitudinal data. In: Linear mixed models in practice: Springer; 1997. p. 63-153.

50. Fahrmeir L, Heumann C, Künstler R, Pigeot I, Tutz G. Statistik: Der weg zur datenanalyse: Springer-Verlag; 2016.

51. lannone R, Allaire JJ, Borges B. flexdashboard: R Markdown Format for Flexible Dashboards. R package version 0.5.1.1. https://CRAN.R-project.org/pa ckage=flexdashboard.

52. euCanSHare project. http://www.eucanshare.eu/. Accessed 25 Mar 2021.

53. NFDI4Health. https://www.nfdi4health.de/. Accessed 25 Mar 2021.

54. Schmidt CO, Krabbe C, Schössow J, Albers M, Radke D, Henke J. Square ${ }^{2}$ - a web application for data monitoring in epidemiological and clinical studies. Stud Health Technol Inform. 2017:235:549-53.

55. Doiron D, Marcon Y, Fortier I, Burton P, Ferretti V. Software application profile: opal and Mica: open-source software solutions for epidemiological data management, harmonization and dissemination. Int J Epidemiol. 2017; 46(5):1372-8. https://doi.org/10.1093/ije/dyx180.

56. Bergeron J, Doiron D, Marcon Y, Ferretti V, Fortier I. Fostering population-based cohort data discovery: the maelstrom research cataloguing toolkit. PLoS One. 2018;13(7):e0200926. https://doi.org/10.1371/journal.pone.0200926.

57. Gessner S, Neuhaus P, Varghese J, Bruland P, Meidt A, Soto-Rey I, et al. The portal of medical data models: where have we been and where are we going? Stud Health Technol Inform. 2017;245:858-62.

58. The Data Nutrition Project. https://datanutrition.org/. Accessed 25 Mar 2021.

59. Simera I, Moher D, Hirst A, Hoey J, Schulz KF, Altman DG. Transparent and accurate reporting increases reliability, utility, and impact of your research: reporting guidelines and the EQUATOR network. BMC Med. 2010;8(1):24. https://doi.org/10.1186/1741-7015-8-24.

60. Sauerbrei W, Abrahamowicz M, Altman DG, le Cessie S, Carpenter J, on behalf of the STRATOS initiative. STRengthening analytical thinking for observational studies: the STRATOS initiative. Stat Med. 2014;33(30):5413-32. https://doi.org/10.1002/sim.6265.

61. Wilkinson MD, Dumontier M, Aalbersberg IJ, Appleton G, Axton M, Baak A, et al. The FAIR guiding principles for scientific data management and stewardship. Sci Data. 2016;3(1):160018. https://doi.org/10.1038/sdata.2016.18.

62. Rubin DB, Little AH. Statistical analysis with missing data. 3rd ed. Hoboken: Wiley; 2020 . 
63. Grimes DA, Schulz KF. Bias and causal associations in observational research. Lancet. 2002;359(9302):248-52. https://doi.org/10.1016/50140-6736(02)074 $51-2$.

64. Schmidt CO, Krabbe CEM, Schossow J, Berger K, Enzenbach C, Kamtsiuris P, et al. Quality standards for epidemiologic cohort studies: an evaluated catalogue of requirements for the conduct and preparation of cohort studies. Bundesgesundheitsblatt, Gesundheitsforschung, Gesundheitsschutz. 2018;61(1):65-77. https://doi.org/10.1007/s00103-017-2658-y.

65. Hoffmann W, Latza U, Baumeister SE, Brunger M, Buttmann-Schweiger N, Hardt J, et al. Guidelines and recommendations for ensuring good epidemiological practice (GEP): a guideline developed by the German Society for Epidemiology. Eur J Epidemiol. 2019;34(3):301-17. https://doi. org/10.1007/s10654-019-00500-X.

66. HL7 FHIR. Documentation index. 2019. http://hl7.org/fhir/documentation. html. Accessed $25 \mathrm{Mar} 2021$

67. Huser V, Kahn MG, Brown JS, Gouripeddi R. Methods for examining data quality in healthcare integrated data repositories. Pac Symp Biocomput. 2018;23:628-33.

\section{Publisher's Note}

Springer Nature remains neutral with regard to jurisdictional claims in published maps and institutional affiliations.

- fast, convenient online submission

- thorough peer review by experienced researchers in your field

- rapid publication on acceptance

- support for research data, including large and complex data types

- gold Open Access which fosters wider collaboration and increased citations

- maximum visibility for your research: over $100 \mathrm{M}$ website views per year

At $\mathrm{BMC}$, research is always in progress. 